\title{
FISTULA FORMATION AFTER TWO STAGED AIVAR BRACKA'S REPAIR FOR HYPOSPADIAS.
}

\footnotetext{
1. FCPS (Plastic Surgery) Assistant Professor Plastic Surgery Nawaz Sharif Medical College Gujrat.

2. FCPS (Plastic Surgery) Assistant Professor Plastic Surgery Rawalpindi Medical University Rawalpindi

3. FCPS (Plastic Surgery) Assistant Professor Plastic Surgery Hayatabd Medical Complex Peshawar.

4. FCPS (Plastic Surgery) Professor Plastic Surgery Quaid-I-Azam Medical College Bahawalpur.
}

Correspondence Address: Dr. Zahid lqbal Bhatti

Assistant Professor Plastic Surgery Nawaz Sharif Medical College Gujrat drzahidbhatti@gmail.com

Article received on:

17/06/2019

Accepted for publication:

$17 / 10 / 2019$

\section{Zahid Iqbal Bhatti', Husnain Khan², Firdous Khan ${ }^{3}$, Mughese Amin ${ }^{4}$}

ABSTRACT... Objectives: To evaluate the frequency of fistula formation after Bracka's repair for hypospadias. Study Design: Retrospective Case study. Setting: Department of Plastic and Reconstructive Surgery, Shaikh Zayed hospital Lahore and Bahawal Victoria Hospital Bahawalpur. Period: 05 years (2014 -18). Material \& Methods: Sixty patients of primary hypospadias underwent two staged Aivar Bracka's repair. Age of patients, type of hypospadias, presence and extent of chordee, donor skin (preputial, post auricular) used, complications and fistula formation were recorded. Leakge of urine from repair site (Primary/Secondary) was noted as fistula formation after 03 weeks postoperatively. Results: A total of 60 patients underwent two staged Bracka's repair. There were 32 patients (53.33\%) with distal hypospadias, 16 patients $(26.67 \%)$ with mid penile and 12 Patients (20\%) with proximal hypospadias. Chordee was present in 33 Patients (55\%). Prepucial skin was used in 46 Patients $(76.66 \%)$ and post auricular skin in 14 Patients (23.34\%) as a donor graft. Four patients (6.66\%) developed fistula. 03 patients $(5.00 \%)$ developed fistula at primary site and 01 patient $(1.66 \%)$ developed at secondary site. Post auricular skin was used as a donor graft in all 04 patients developing fistula. Conclusion: Two staged Bracka's repair is a versatile technique and reliable procedure for hypospadias repair with minimal complications and is applicable to all types of hypospadias due to excellent functional and cosmetic outcome.

Key words. Aivar Bracka, Chordee, Hypospadias.

Article Citation: Bhatti ZI, Khan H, Khan F, Amin M. Fistula formation after two staged Aivar Bracka's repair for hypospadias. Professional Med J 2020; 27(4):790-795. DOI: 10.29309/TPMJ/2020.27.04.3820

\section{INTRODUCTION}

Hypospadias is one of common congenital anomalies occurring 1 in 300 male children. Urethral opening is on ventral aspect of the penis or in the perineum and is associated with the absence of distal urethra and corpus spongiosum. ${ }^{1}$ The diagnosis is quite apparent and can be made at birth. Patients experience various degree of functional disabilities. The stream may be deflected ventrally. ${ }^{2}$

The correction of hypospadias remains one of the most challenging problems. More than 300 procedures have been described but none of these procedures can be universally applied to all types of hypospadias. ${ }^{3}$ Complications from surgery for hypospadias are post-operative bleeding, loss of skin graft loss, skin flap necrosis, fistula formation, urinary stricture, meatal stenosis / retraction, hypertrophic scar and ugly scar. ${ }^{4}$
Out of many post-operative complications, fistula formation is the most common and ranges from 5 to $45 \%$ depending upon the stage and type of procedure. This also points out the prognosis of the procedure..$^{5}$ Various factors are implicated in fistula formation such as infection, trauma, poor healing rough handling, tension over repair and in appropriate use of suture. ${ }^{6}$

Fistula is not due to faulty technique but other factors like back pressure, turbulance, skin bridges, hair on neo urethra. ${ }^{7}$ Due to fistula, the person faces social, functional problems like poor stream during urination, wetting of cloths, and as well as aesthetic problems. The risk of urinary tract and penile soft tissue infection is also increased. $^{8}$

The two staged Bracka's of hypospadias is a versatile technique and is applicable to all types of 
hypospadias even in salvage cases with minimal complications with full thickness graft in $1^{\text {st }}$ stage as a urethral plate for urethral reconstruction. We routinely use two staged Aivar Bracka's repair for all types of hypospadias and get good results as compared to other procedures. The objective of this study is to evaluate the frequency of fistula formation after two staged Bracka's repair for hypospadias

\section{MATERIAL \& METHODS}

This study was conducted at Burn \& Plastic and reconstructive unit of Aziz Bhatti Shaheed Teaching Hospital Gujrat and Bahawal Victoria Hospital Bahawalpur Pakistan over a period of 05 years (2014 -18).

A total of 60 patients of all types of primary hypospadias undergoing Bracka's repair were included in the study. A through history and physical examination including age, site, type of hypospadias, presence and extent of chordee, quality and quantity of donor skin were recorded preoperatively. The patients were followed up on $2^{\text {nd }}$ week, $6^{\text {th }}$ week, 3 month and 6 months. The fistula was suspected as leakage of urine through any opening other than urinary meatus and confirmed by applying soft catheter around the base of penis and injecting normal saline through meatus and observing leakage of urine.

During the first stage, all patients underwent Bracka's hypospadias repair under general anaesthesia and tourniquet control around base of penis proximal to ectopic meatus if space available. The degree of chordee was assessed by Horton's test. An axial and two lateral incisions were made from ectopic meatus to proposed dorsal limit of new urethra and in subcoronal area from midline. The preputial skin is harvested if adequately available; otherwise post auricular skin is used to cover raw area. The marked area of prepuce was incised, dissected and thinned out over finger to remove surplus connective tissue. It was stored in normal saline soaked guaze. Midline and lateral incisions are made and dissection is done up to distal limit of two corpora cavernosa. Horton test is performed again after removal of fibrous tissue till penis becomes straight. The donor skin was placed and tie over dressing was applied and fixed with $4 / 0$ prolene suture. Foley catheter was removed on $2^{\text {th }}$ postoperative day and tie over dressing was removed after 5th day. The patient was discharged with the instructions of wound care, excessive drinking water, urination and follow up. After 6 week, patient was advised about method of massage of the graft and application of some lubricant. The patient was followed up every month for 6 months to see the condition of the graft.

During $2^{\text {nd }}$ stage, the patient was re admitted 6 months after $1^{\text {st }}$ stage and assessed physically and graft wise. After anaesthesia, Horton test was performed to confirm that correction was adequate. $A \cup$ shaped incision over the skin is marked with care to make tube easily. Silicone catheter was passed and tourniquet was applied. Incision was made and dissection was done up to dorsal surface to allow mobilization of skin envelop along buck's fascia plane down to level proximal meatus. The tube was made comfortably without tension. The meatus was reconstructed first by joining ventral points with 7/0 (Polydioxanone) PDS. Rest of urethral tube was made with combination of interrupted and continuous sutures.

A proximal based flap of subcutaneous tissue was raised from dorsal hood and transposed ventrally to cover reconstructed tube and fixed with $7 / 0$ (Polydioxaone) PDS suture. This flap formed Waterproofing and is used to cover the first layer taking care that two layers are separated from each other. The skin was closed as a third layer. The tourniquet was released to see bleeding and haemostasis was done with bipolar cautry. A dressing is done around penis and left in place for seven days. The Foley's catheter secured safely on abdominal wall and removed on $7^{\text {th }}$ day.

\section{RESULTS}

Mean age was 5.5 years with (range 2-10 yrs). 32 patients $(53.33 \%)$ were of distal, 16 patients (26.67\%) of mid penile and 12 patients (20\%) of proximal hypospadias. Chordee was present in 33 patients $(55.00 \%)$ and absent in 27 Patients (45\%). As a graft, preputial skin was used in 46 
$\%$ patients (76.66\%) and post auricular skin in 14 Patients (23.34\%). Out of total 60 patients, total complications developed in 11 patients (18.33\%). Hematoma in $02 \%$ (3.33\%), urinary retention in 03 patients $(5.00 \%)$, wound dehiscence in 02 Patients (3.33\%) and fistula developed in 04 patients (6.6\%), 03 patients (05.00\%) developed on primary site and 01 patient (1.66\%) at secondary site.

\begin{tabular}{|c|c|c|c|}
\hline Sr. No. & Age (Yrs) & $\begin{array}{c}\text { No. of } \\
\text { Patients }\end{array}$ & $\begin{array}{c}\text { Percentage } \\
\%\end{array}$ \\
\hline 1. & $2-4$ & 22 & 36.66 \\
\hline 2. & $5-6$ & 19 & 31.66 \\
\hline 3. & $7-8$ & 11 & 18.33 \\
\hline 4. & $9-10$ & 08 & 13.33 \\
\hline 5. & Total & 60 & 100.00 \\
\hline & \multicolumn{2}{|c|}{ Table-I. Age distribution of patients. } \\
\hline
\end{tabular}

\begin{tabular}{|c|c|c|c|}
\hline Sr. No. & $\begin{array}{c}\text { Type of } \\
\text { Hypospadias }\end{array}$ & $\begin{array}{l}\text { No. of } \\
\text { Patients }\end{array}$ & $\begin{array}{c}\text { Percentage } \\
\%\end{array}$ \\
\hline 1. & Distal Penile & 32 & 53.33 \\
\hline 2. & Mid Penile & 16 & 26.67 \\
\hline 3. & Proximal Penile & 12 & 20.00 \\
\hline 4. & Total & 60 & 100.00 \\
\hline \multicolumn{4}{|c|}{$\begin{array}{c}\text { Table-II. Types of hypospadias. } \\
\text { Total Patients. } 60\end{array}$} \\
\hline Sr. No. & $\begin{array}{l}\text { Significant } \\
\text { Chordee }\end{array}$ & $\begin{array}{l}\text { No. of } \\
\text { Patients }\end{array}$ & $\begin{array}{c}\text { Percentage } \\
\%\end{array}$ \\
\hline 1. & Present & 33 & 55.00 \\
\hline 2. & Absent & 27 & 45.00 \\
\hline 3. & Total & 60 & 100.00 \\
\hline \multicolumn{4}{|c|}{$\begin{array}{l}\text { Table-III. Chordee. } \\
\text { Total Patients. } 60\end{array}$} \\
\hline
\end{tabular}

\begin{tabular}{|c|c|c|c|}
\hline Sr. No & Graft Site. & $\begin{array}{c}\text { No. of } \\
\text { Patients }\end{array}$ & $\begin{array}{c}\text { Percentage } \\
\%\end{array}$ \\
\hline 1. & Preputial skin & 46 & 76.66 \\
\hline 2. & Post Auricular Skin & 14 & 23.34 \\
\hline 3. & Total & 100 & 100.00 \\
\hline & $\begin{array}{r}\text { Table-IV. Donor site for graft. } \\
\text { Total Patients. } 60\end{array}$ \\
\hline
\end{tabular}

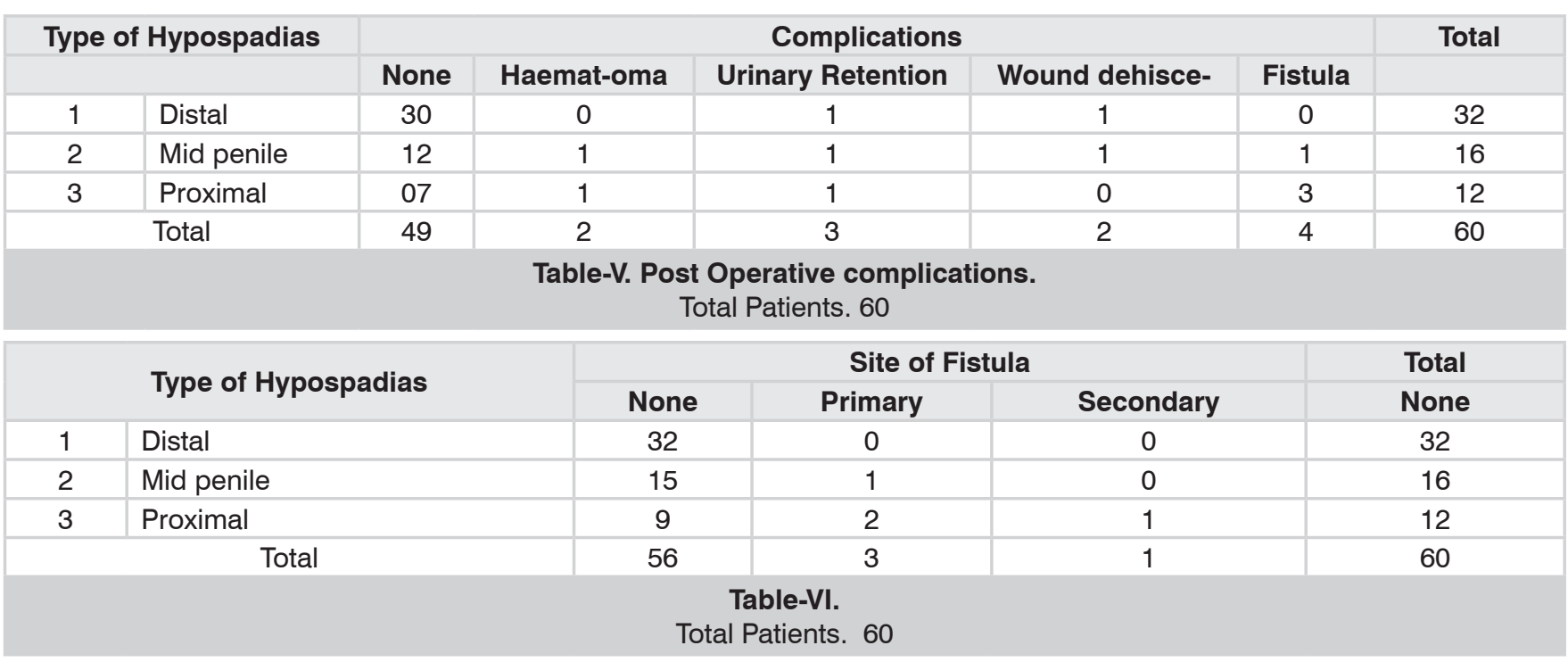

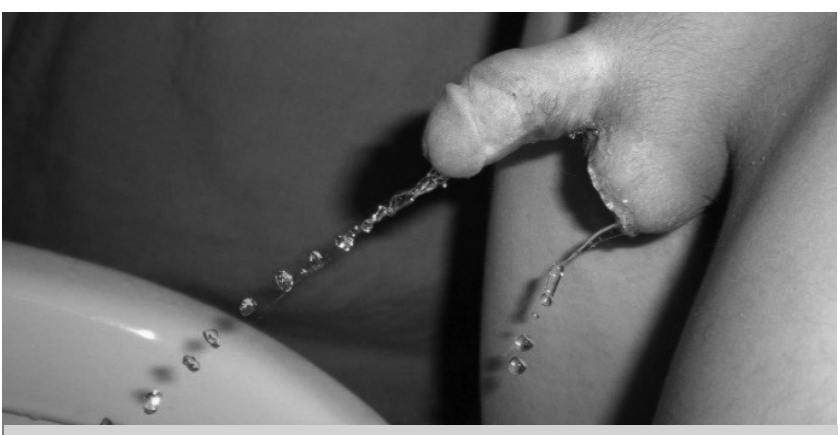

Fistula in Proximal Hypospadias.

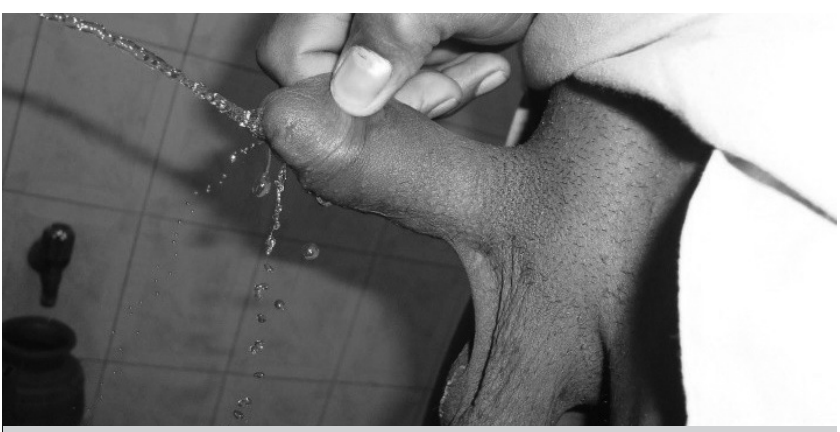

Fistula in Distal Hypospadias 


\section{DISCUSSION}

The surgical goal in patients with hypospadias is to construct a straight penis with meatus as close as possible to normal site to allow forwarded directed stream and normal coitus. ${ }^{9}$ Among a large number of surgical procedures for hypospadias, two staged Bracka's repair is one of the most effective method to achieve above goals. A large numbers of complications are associated with hypospadias repair. Among common and uncommon postoperative complications, fistula formation is most common. ${ }^{10}$

Fistula formation after hypospadias repair is a parameter of success in any type of procedure whether it is a single or two staged procedure. Fistula formation after repair must be viewed in context of an overall evaluation of repair. The evaluation should include final meatal position and shape, urinary stream and straightness on errection. ${ }^{6}$ Postoperative fistula caused too much embarrassment for the surgeon as well as for parents. Various factors are implicated in fistula formation such as infection, trauma, poor healing, rough tissue handling, excessive use of cautery, too much tension over repair and inappropriate use of sutures. ${ }^{11}$ Apart from above factors, fistula formation is not due to faulty technique but also unseen factors like back pressure, turbulence, increased sheared stress due to narrowing, skin bridges, hair on irregular surface of urethra. ${ }^{12}$ Despite careful pre- operative evaluation and planning, meticulous surgical technique, optical magnification, skilled assistance and modern material, a proportion of patients continue to suffer this complication. ${ }^{6,13}$

In two staged repair of hypospadias, multiple options are available to form tube for neo urethra like prepucial skin, hairless skin (post auricular skin), urinary bladder mucosa, buccal mucosa and tunica vaginalis. ${ }^{14}$ In the present study, most common graft used for neourethra was prepucial skin due to its availability, pliability and thinness and was used in $46 \%$ (76.66\%) and post auricular skin in 14 patients (23.34\%). Tahmeedullah et al. mentioned very good results of prepucial skin relating to it take and rate of fistula formation is very low as compared to post auricular skin and buccal mucosal graft. He gave his postoperative fistula rate $3.12 \%$ of prepucial skin, $5 \%$ of postauricular skin and $5.8 \%$ of buccal mucosa graft as compared to $5.1 \%, 13.6 \%$ and $8.8 \%$ respectively. ${ }^{15}$ Manzoni et al. reported 67 patients in which prepucial skin was used as a free graft in 46 patients and graft from other sites in 21 patients in case of poorly developed/ absent prepuce. ${ }^{16}$

In this study, fistula developed in 04 patients (6.6\%) after two staged bracka's repair. This study is comparable to original Aivar Bracka's study in 1995 , Fistula were reported to be $10.5 \%$. Out of total 04 fistulas, 03 fistulae developed in proximal hypospadias and 01 in middle hypospadias. Out of total 04 fistulae 03 patients developed fistula at primary site (site of ectopic meatus) and 01 developed at secondary site (other than ectopic meatus). ${ }^{17}$ Holland $A$. J et al. observed increased incidence of fistula formation risk in proximal hypospadias. ${ }^{6}$ In 2005, Obaidullah and Aslam applied two staged bracka's repair on 1206 cases and reported over all fistula rate $5.9 \% .^{11}$

As most of the hypospadias are of distal type (50-70\%) but urethrocutaneous fistulae develop frequently in complex repair of middle and proximal hypospadias. ${ }^{18}$ In this study, 03 fistulae $(75 \%)$ of developed in proximal and 01 fistula $(25 \%)$ of the total 04 fistulae developed in middle hypospadias. In 2007, Hansson et al. observed about $87 \%$ of fistulae develop in proximal and middle hypospadias. Marraco also noted increased complications in proximal hypospadias. ${ }^{19}$

Risk factors to develop fistula include proximal type, presence and extent of chordee, increasing age, haematoma, urinary distal obstruction, wound dehiscence, tension over repair, failure of inverted margins, inappropriate suture material and ischemia. ${ }^{6}$ The $2^{\text {nd }}$ layer of neourethra (Proximally based Dartos fascia from dorsolateral aspect of penis) between skin and graft is very important to reduce fistula formation. In 2005, Aslam and Obaiudullah reported the importance of fascia from venterolateral aspect of phallus in 
order to reduce operative time and morbidity and fistula. ${ }^{20}$

Fistula complication accepted by surgeons of average about $10-20 \% .{ }^{21}$ Our results are comparable to other studies. Ahmed $\mathrm{M}$ et al. had fistula rate of about $10.7 \%$ after two staged hypospadias repair. ${ }^{22}$ Weinberg et al. noted $77.7 \%$ of total complications rate with fistula formation in $44.4 \% .{ }^{23}$ Snodgrass noted $13.33 \%$ fistula rate in total complication of $20 \%{ }^{24}$ Using Snodgrass technique, Shanberg achieved good result with fistula rate $7.69 \%$ and Yang got fistula rate of about $28 \%$ with same technique. ${ }^{25}$ In 2005 , Caken et al. observed fistula rate of $21.6 \%$ within previous reports between $15-33 \% .{ }^{24}$ While Bracka's himself described fistula rate of $5.7 \%$ in 1995. ${ }^{26}$

\section{CONCLUSION}

It is concluded that two staged Bracka's repair is a versatile, unique and reliable procedure and is applicable for all types of hypospadias with minimal complications as compared to other procedures. It not only produces a normal looking slit like meatus but also almost scar less ventral surface of penis. Moreover, the appearance of penis is acceptable for patients as well as for surgeon. Due to excellent results, Bracka's procedure can be promoted as a repair of hypospadias.

Copyright@ 17 Oct, 2019.

\section{REFERENCES}

1. Arshad AR. Hypospadias repair: Bayer's two staged operation revisited. Br J Plast Surg 2005; 58:481-6.

2. Kiss A, Nyirady P, Merksz M. Combined use of para meatal based meatoplasty (Mathieu) with midline incision on urethral plate in hypospadias repair. Eur J pediatr Surg 2007; 123:383-5).

3. Obaidullah, Aslam M, Ten years review of hypospadias surgery from a single centre. Br J Plast 2005; 58: 7809).

4. Mishwani A H, Ahmed M, Burney R B. Hypospadias; one stage repair. Pak armed Forces Med Jr. 2003; 53: $148-52$.
5. Ahmed F, Alvi MS, Rana Mr. Tubularized incised plate urethroplasty for various types of hypospadias. Pak Armed forces Med J 2007; 56-60.

6. Holland A, Abubackar M, Smith G, Cass D. Management of urethrocutanous fistula following hypospadias repair. Pediatr Surg int 2008; 24; 1047-51.

7. Shanberg A M, Sanderson K, Duel B. Re operative hypospadias repair using Snodgrass incised plate urethroplasty. B J Int. 2001: 87: 544-47.

8. Sripathi V, Sathesh M, Shuba K. Salvage hypospadias repair. J Indian assoc Pediatr Surg 2008; 13: 132-36.)

9. Rasool M, Shaikh A H, Tabassum S A, Amin M M. Hypospadias repair. Profes Med J 2007; 14:677-84.

10. Bhat A, Mandal AK. Acute postoperative complications of hypospadias repair. Indian J Urol 2008; 24:780-9.

11. Beadudoin S, Delaage $p \mathrm{H}$, Bargy f. Anatomical basis of surgical repair of hypospadias by spongioplsty. Surg Radio Anat. 2000; 22: 139-41.

12. Shanberg A M, Sanderson K, Duel B. Re operative hypospadias repair using Snodgrass incised plate urethroplasty. B J Int. 2001; 87: 544-47.

13. Sunay $M$, dadali $M$, Karabulut $A$, et al. Our 23 years' experience in urethrocutaneous fistula after hypospadias surgery. Urol 2007; 69: 366-8.

14. Weinburg G, Williot $P$ E, Leonard M P. The utility of buccal mucosa graft in salvage urethroplasty. Can $\mathrm{J}$ urol 2000; 9: 1641-5.

15. Tahmeedullah, Khan AT, Obaidullah M A. Comparision of prepucial skin, post auricular skin and buccal mucosa graft results in hypospadias repair. J Coll Pyysicians Surg Pak 2003; 13: 515-8.

16. Manzoni G, Bracka A, Palminter E and Morrocco G. Hypospadias surgery. When, what and by whom?. B J U Int. 2004; 94: 1188-95.

17. Bracka A. Hypospadias repair. The two staged alternative. B J U. 1995; 76: 31-41.

18. Park JM, Bloom DA, (2006) Hypospadias repair. Int: Spitz L, Coran AG (eds) Operative Paediatric Surgery. Hodder Aenold p.841-69.

19. Anderson B, Mitchel $M$, Recent advances in hypospadias: current surgical technique and research in incidence and etiology. Curr Urol Rep $2001 ; 2: 122-6$. 
20. Aslam A, Obaidullah, Mumtaz N. A modified waterproofing layer in two staged hypospadias repair: Five years' experience. Pakistan J Med Res 2005; 44: 27-31.

21. Aslam M, Obaudullah, Majid A. A two staged Aivar Bracka's repair in hypospadias salvage cases. J Postgard Med Inst 2006; 20:203-6.

22. Ahmed M, Hussain A, Azim W, Saeedudin. A two staged hypospadias repair, a method applicable to all types of hypospadias. Jr Coll Physician Surg Pak 2008; 13: 226-8.
23. Weinberg G, Williot $P$ E, Lenord M P. The utility of buccal mucosa graft in salvage urethroplasty. Can $\mathrm{J}$ Urol. 2000; 9: 1641-5.

24. Caken M, Yalcinkaya F, Demirel F, Aldemir M, Altug U. The midstream success of tabularized incised plate urethroplasty in reoperative patients with distal and mid penile hypospadias. Pediatr Surg Int 2005; 21 : 973-76.

25. Yang S S, Chen S C, Hsiech C H, Chen H T. Reoperative Snodgrass procedure. J Urol 2001; 166: 2342-5.

26. Hardwicke J, Clarkson J, Park A. Centralization of hypospadias service - The Warwickshire experience. J Plast Reconstr Surg 2007; 60: 61-63.

\begin{tabular}{|c|c|c|c|}
\hline \multicolumn{4}{|c|}{ AUTHORSHIP AND CONTRIBUTION DECLARATION } \\
\hline Sr. \# & Author(s) Full Name & Contribution to the paper & Author(s) Signature \\
\hline 1 & Zahid lqbal Bhatti & Collection of data \& Writing. & acell. \\
\hline 2 & Husnain Khan & $\begin{array}{l}\text { Collection of data \& Analysis } \\
\text { tool. }\end{array}$ & \\
\hline 3 & Firdous Khan & Performed analysis. & \\
\hline 4 & Mughese Amin & $\begin{array}{l}\text { Performed the analysis \& } \\
\text { guidance. }\end{array}$ & - 10 \\
\hline
\end{tabular}

